\title{
The Concept of Knowledge: What is It For?
}

\author{
Jesús Vega-Encabo \\ Universidad Autónoma de Madrid \\ BIBLID [0873-626X (2016) 43; pp. 187-202]
}

DOI: 10.2478/disp-2016-0011

\begin{abstract}
What is the concept of knowledge for? What does it do for us? This question cannot be severed from considerations about what we do by using it. In this paper, I propose to view the point of our concept of knowledge in terms of a device for acknowledging epistemic authority in a social and normative space in which we share valuable information. It is our way of collectively expressing the acknowledgment we owe to others because of their being creditable when engaged in the task of knowing. By using the concept of knowledge we are not just marking the epistemic positions we occupy, we are also acknowledging epistemic authority and indicating the advisability of taking oneself or others as "ready" for the transmission of authority.
\end{abstract}

\section{Keywords}

Concept of knowledge, certification view, credibility, epistemic authority, acknowledgment.

\section{Introduction}

The analytical project in epistemology has been undertaken with the prospect of elucidating the very nature of knowledge by conceptual analysis. Maybe the assumption behind the project is that our concepts reflect (though maybe imperfectly) the structure of reality. So does our concept of knowledge. Hence the lure of a project that seeks to provide necessary and sufficient conditions for knowledge. It would reveal what knowledge is.

Edward Craig in his fascinating book Knowledge and the State of Nature (1990) has proposed to refocus traditional concerns in epistemology and move from the analytic project towards a new synthetic one in which the point and the purpose of our concept of knowledge

Disputatio, Vol. VIII, No. 43, November 2016

Received: 19/07/2016 
play the main role. What is the concept of knowledge for? What does it do for us? This question cannot be easily severed from considerations about what we do by using it. This will be the focus of my paper. Nothing in it should be understood as giving a key to grasping its content. I don't believe that just focusing on our uses or on the presumed point of the concept is enough to determine its content. Nevertheless I will try to argue for a sort of functional account of our concept of knowledge in which its actual uses are central. I will hold that the purpose of the concept is better understood as a device for acknowledging epistemic authority in a social and normative space in which we share valuable information. If paying attention to the concept of knowledge is of epistemological significance, it is mainly because the very introduction of this conceptual resource transforms the cognitive practices of a community.

The paper proceeds as follows. In the next section, I present some reasons why we should care about the role of the concept of knowledge. The phenomenon of human knowledge is shaped by the very conceptual resources we deploy to talk about it. After that, I discuss two recent accounts on the point of the concept: the certification view and Brandom's expressive view. Both provide core features of our concept and hide others, particularly the need that knowledge should mark an achievement in which agents deserve credit for attaining the truth. The last two sections develop my own view on the point of the concept: first, by distinguishing between what I will call a space of epistemic positions and a space of credibility, I claim that one of the points of the concept derives from the need to detect the gap in our projection of one space towards the other. Secondly, by focusing on first-person uses of the concept, I argue that its point is to single out those performances of the epistemic agent that are creditable, in such a way that they serve as an authority for others.

\section{Why care about the role of the concept of knowledge?}

The concept of knowledge is pervasive, evaluative, agential, and objective. Pervasive and ubiquitous: 'know' is one of the most used verbs, appears in every language and is learned very early in infancy (Nagel 2014). Evaluative: 'know' is used to assess the life of cognitive agents; when we state that someone knows, either because 
one claims oneself to know or because one attributes knowledge to others, we are presupposing that certain standards or norms have been met. Agential: agents engaged in cognitive tasks and practices are the primary units of epistemic assessment; in general, epistemic evaluation has to do with how agents get the truth (Sosa 2007). Finally, objective: there must be an objective answer to the question of when the concept has been correctly applied.

So it does not seem contentious to me that the notion of knowledge plays a central role in our conceptual scheme and in our intellectual and practical life. But this set of features that shapes the importance of the concept does not answer by itself the significance of enquiring about the point and the purpose of the concept. Why expect that an answer to the question about what it does for us, as Craig used to say, or what we do with it, as I like to frame it, will be illuminating about knowledge itself?

Remember Craig:

Knowledge is not a given phenomenon, but something that we delineate by operating with a concept which we create in answer to certain needs, or in pursuit of certain ideals. The concept of water, on the other hand, is determined by the nature of water itself and our experience of it (Craig 1990: 3).

This remark needs to be correctly understood: first, the interest in the human phenomenon of knowledge lies in the fact that we primarily learn what knowledge is within a social and cultural niche and that we do it by responding to our experience as cognitive beings that exchange information and cooperate on the basis of shared information within a context where there sometimes exist strong informational asymmetries; second, the possession of the concept of knowledge contributes to transforming our cognitive and epistemic practices within this social and cultural niche. The very phenomenon of knowing is shaped by our use of the concept of knowledge, a use that perhaps answers to certain needs or ideals, as Craig says, to certain demands that are couched in the social and practical role the concept plays within the human ecological niche.

This reading delineates a view that takes social cognitive ecology 
seriously. ${ }^{1}$ The main focus should be on those practices that turn around the acquisition of information and their evaluation in a social and cultural setting. But this has to be completed by a view on how normative domains take over these practices characteristic of an information-sharing social species (Sosa 2011, 2015) or "highly gregarious, deeply interdependent cognizers" (Kusch 2011). There is no contradiction in claiming that knowledge is a sort of "ecological kind" and that our concept of knowledge responds to social epistemic norms set by needs encountered within our ecological niche. We build our ecological niche by engaging in the transformation of our practices and our epistemic conceptual resources are crucial tools in building a human cognitive niche.

\section{The certification view}

Literature has provided us with a plethora of proposals about the role and purpose of the concept of knowledge. Rorty, in his classic Philosophy and the Mirror of Nature (1979), introduced the idea that epistemic concepts serve to praise and blame the subject and that this explains its role in social practices. Blackburn writes in the same spirit: "We need a role for the epistemic concepts, and the role which seems most natural is that of ranking and selecting titles to respect" (1984: 169-70). Along the same lines, Brandom has proposed that epistemic concepts are expressive concepts that make explicit our commitments and responsibilities in discursive practices (Brandom 1994, 2000, 2010). Austin used to say that the notion of knowledge plays the role of giving assurance to others (Austin 1949). Craig has introduced an especially influential view: the concept of knowledge fulfills some needs in our social cognitive ecology; its point is mainly to flag good informants and approved sources of information (Craig 1990, Sosa 2011, Greco 2012). More recently, some other roles have been proposed, like regulating inquiry (the concept of knowledge indicates when the agents may/ought to end their inquiry, Kappel 2010 and Kelp 2011) or distinguishing between kinds of blame for violating normative expectations in cooperative settings (Beebe 2012).

It is not my intention to add a new item to this list; in fact, I do

${ }^{1}$ See Gerken, Kallestrup, Kappel and Pritchard 2011. 
not see them as fully incompatible. I think that there is much convergence in the facts they point to, and probably the concept of knowledge does not answer to a unique need or set of needs (Beebe 2012). My aim is to indicate how the illumination of the practical role of the concept of knowledge is crucial to our understanding of how our epistemic conceptual doings contribute to shape our cognitive practices. The important thing is how we view each other as knowers when we participate in a community where epistemic standings are identified by using such a tool as the concept of knowledge.

Among the proposals that I have just mentioned, two stand out as more promising for this task: the first, that has been called by Kelp (2011) the certification view (see also Kappel 2010), provides a practical explanation of the concept of knowledge as having the function of being an inquiry-stopper; the second understands the concept of knowledge as an expressive tool that makes explicit what is implicit in social discursive practices (Brandom 2010). Both of them give us some hints about how the concept of knowledge transforms our practices of inquiry and information-sharing. Both of them seem to me, however, insufficient or incomplete.

Just a few words about the certification view. The central idea is that the concept of knowledge helps us to indicate adequate inquiry stoppers, a need that derives from our concerns with truth, the costs associated with pursuing inquiries to establish truths and the fact that there is no natural stopping position (Kappel 2010). The point of the concept is given by the recognition that we need a device to express "the attitude that our epistemic position with respect to a particular proposition is now so good that we should stop further enquiry whether $p$ " (Kappel 2010: 77). There is a remarkable difference with other proposals along the same lines: Kelp (2011), for instance, formulates that need in terms of permissibility and not in terms of obligation. The role is to indicate when the agent "may end the inquiry" or, in other words, when it is (epistemically) permissible for him to take the proposition as true. It is certainly valuable for us to have predicates that express epistemic evaluations of our epistemic positions and one of them is the knowledge-predicate, whose role is to make judgments about when someone is in a sufficiently good epistemic position such that one may/ought to take the truth of $p$ for granted in one's practical and theoretical deliberation (this is a modification of 
Kappel 2010: 79).

This view is clearly aligned with the main tenets of Craig's proposal. The point of the concept is to flag approved sources of information, that is, where to look for in order to get reliable information. This need is fulfilled by an ancestor of our concept of knowledge, which following Kusch we can call 'proto-knowledge' (Kusch 2011). Remember that this ancestor is anchored to perspectival and purpose-relative needs; so a process of objectivisation is required to get our concept of knowledge. But to evaluate informants is not the only need within a social cognitive niche. We also need to evaluate inquiries undertaken by epistemic subjects. So we can also develop a notion of protoknowledge whose function is "to flag when agents may adequately terminate inquiry" (Kelp 2011). The idea is that this function also has to be conceived as not purpose-relative. It is easy to see that the end of our inquiry can be motivated by many different reasons, not all of them having the required epistemic import. There is also here a huge diversity and variability of interests that could enter into our judgments about when the inquiry may, or even should, terminate. Our concept of knowledge should abstract away from these vagaries of inquiry; and it is difficult to see how the pressure to objectivisation could finally give us a concept that exclusively responds to epistemic concerns and evaluations, as the concept of knowledge seems to do.

Moreover, we have many other epistemic concepts that could adequately answer to this need of appropriate inquiry-stoppers. For instance, a concept that reflects either justification to such a degree that it is not expected that any further considerations could reasonably undermine the belief that $p$, or the acquisition of enough coherence for our system of beliefs to remain stable. That could be sufficiently good to stop the inquiry; however, it is far from clear that this captures what is essential in our concept of knowledge. Let us consider the issue at stake in other terms: what we need is a notion around which agents can coordinate their assessments, that is, that points to social epistemic norms that answer to the needs of an information-sharing social species (Sosa 2015: 170). Our epistemic judgments about when someone is in a sufficiently good epistemic position go together with the satisfaction of a set of objective standards. These do not need to be built into our notion of knowledge, 
but they crucially shape the epistemic normative domain. It is true then that the coordination of our endeavours would benefit from a notion that marks when to stop (even provisionally) our deliberations and inquiries such that our epistemic standings can be considered as sufficiently good. This could help in the identification of reliable believers and (once other social conditions are secured) of reliable (and trustworthy) informants. But the crucial point is how these agents take part in the epistemic normative domain, that is, how they secure the acquisition of truths through the exercise of their competences. What we need is a notion that marks an achievement and the construction of a cognitive niche where achievements are recognized as particularly valuable.

\section{The concept of knowledge as an expressive tool}

Brandom's expressivism about epistemic concepts is worth discussing at this point. We can draw some lessons from the way Brandom approaches the social and practical role concepts play in our discursive practices.

(i) Brandom places doings at the foreground and particularly doings within discursive practices. At their core, we find assertions and judgments, as units of understanding and knowledge. Asserting and judging are both conceptual practices and implicit epistemic claims. The epistemic dimension of discursive practices is already given with conceptual application. Conceptual practices are epistemic practices even if we are not able to describe them by using explicit epistemic terms, that is, by deploying concepts like knowledge, justification, or reliability.

(ii) Now Brandom is also interested in the vocabulary that serves us to talk about our discursive practices as epistemic. Remember: asserting or judging that $p$ amounts to implicitly claiming to know that p. But our language includes expressive concepts whose main role is to make explicit what remains implicit in our doings. Epistemic concepts play an expressive role of that sort. Their function is not to describe a special state or act of cognition but to allow their users to make explicit what remains implicit in our claims to know, that is, at the core of our discursive practices.

(iii) The concept of knowledge, then, is an expressive tool to 
make explicit implicit epistemic claims within a social space of practical attitudes and normative statuses. This adds an important strand to Brandom's thought. A normative status, and knowledge seems to be one, is always instituted by social practices. Here Brandom exploits a Rortyan motive. It seems obvious form this line of thought that reality itself cannot exert rational authority on us, neither in practical matters nor intellectual ones. Epistemic authority does not grow from our cognitive responses to the world; it is constituted by social responses in terms of mutual practical attitudes (commitments, undertakings of responsibility, acknowledgement and attribution). When we attribute a normative status, what we are doing is attributing a status instituted through social practices. In no relevant sense can this status grow out of our responses to how the world is.

So far so good. Now the use of an epistemic concept such as knowledge through an attribution to another subject makes explicit something that is implicit in our doings. In Brandom's view, if such a concept is normative and therefore socially instituted, it has to reflect an interplay of practical attitudes. The schema matches the wellknown true justified belief account in the following way. By saying that $S$ knows that $p$, what we are doing is to make explicit this set of practical attitudes: (i) the attribution of a commitment to $p$ or taking-true that $p$; (ii) the attribution of an entitlement to that commitment; (iii) my undertaking the commitment that I attribute (endorsing that $p$ ).

One interesting feature of this conception is that my perspective on the issue whether $p$ (and I want here to understand my epistemic perspective) is involved in any attribution of knowledge. I cannot attribute knowledge that $p$ to someone without at the same time endorsing $p$. Implicit knowledge claims also involve this interplay of perspectives. I cannot view myself as a knower, or so we should assume, without taking into account this exchange of attitudes between the epistemic perspectives of many actors. I cannot claim to know without viewing my commitment as being available for another epistemic agent to undertake it. ${ }^{2}$ We seem to deploy the concept of knowledge in order

${ }^{2}$ This does not mean that I cannot think I know something that nobody knows except me. Nevertheless, any claim to know is part of an interplay of perspectives between epistemic subjects, in such a way that implicitly I need to view my claim as involving a commitment that others should be disposed to undertake. Thanks to Javier González de Prado to draw my attention to this. 
to indicate that we share beliefs on a certain issue and under certain circumstances which have to do with the entitlements to believing thus and so. It makes sense to me the idea that if there is a normative status involved in our discursive practices something about the mutual perspectives of the epistemic agents needs to be taken into consideration. The question is whether the normative epistemic status of knowledge one explicitly attributes can be understood without strengthening as well the link between the epistemic standings of each cognitive agent and the fact that they answer to how the world is. That is, without taking into consideration how we do take them to get the truth.

As we have seen, each assertion or judgment incorporates an implicit knowledge claim. One would make it explicit by deploying the concept of knowledge in first-person uses. Which practical attitudes are involved in the first-person case? One could say: I am taking myself as committed and entitled to $p$ (what amounts to a disposition to attribute myself these commitments and entitlements) and obviously I am willing to undertake (endorse) this commitment. But here there is no apparent interplay of perspectives. For Brandom, this would mean that the truth-condition has no bearing. Remember, for him, "all that condition is doing is marking the coincidence of belief across social perspectives: I only count as knowledge beliefs that I share" (2009: 158). A reading coherent with this idea is that taking myself to be a knower is just to have the disposition to attribute to myself a commitment that I endorse and an entitlement to that commitment. Clearly this does not completely fit with Brandom's views: taking myself to be a knower requires the (perhaps internalized) perspective of others sharing my commitments (not necessarily my entitlements), that is, pertaining to the same community of believers. Truly enough, 'knower' is not a title that I can bestow to myself. Yet I can view myself as deserving this title. But if this is so, the question is: in virtue of what do I deserve it? It seems clear to me that the response cannot be that others would endorse the very same belief.

\section{Epistemic standings and credibility}

The remarks of the last section are not intended as an objection to Brandom's view. My aim was to motivate a distinction that I think 
important in our understanding of the role that the concept of knowledge plays in our discursive practices. It is the distinction between $a$ space of epistemic positions or standings and a credibility space. Every cognitive subject occupies an epistemic standing regarding a proposition or field of propositions by the very fact of meeting shared standards of epistemic assessment. The relations among different cognitive subjects established according to differences in epistemic standings build a space of epistemic positions. A credibility space is basically fixed through the attitudes that participants in practices of information sharing and evaluation have towards other subjects regarding their possible epistemic standings. The distinction takes seriously the idea of deserved epistemic merit without having to renounce seeing the social and practical dimension of our bestowing of epistemic titles.

Now I take both spaces as being relationally constituted. On the one hand, it is clear that the credibility space is essentially relational, because it is defined by mutual attributions and recognitions within a social cognitive niche. On the other hand, the space of epistemic positions is built through assessments that refer to sufficiently good epistemic positions, as they intervene in the certification view previously discussed. Nothing requires that this space be built as a space of absolute positions, where a sufficiently good epistemic position, one that answers to the normative standards whose satisfaction constitutes deserved epistemic merit, would be independent of any other position in the very same space. I consider this space, at least implicitly, as relational insofar as it is constituted by strong asymmetries in the capacities to acquire and exchange reliable information. But nothing in my argument depends on this understanding.

The important thing is that both spaces can remain, and in fact very often they are, disconnected at some points. I claim that this fact is reflected in the correct use of our epistemic vocabulary. Having learned the concept of knowledge, we should be disposed to recognize that taking someone as having beliefs that others consider credible may not match the deserved epistemic merit. On the one hand, those beliefs for which we obtain some credibility at the social level could be far from complying with characteristic normative features of our beliefs: they could be unsafe, Gettierized, or irresponsible (even in terms of the discursive practices). On the other hand, there 
could be spaces of epistemic credibility and authority that are extremely deformed by social forces. Our credibility judgments could not adequately track the epistemic positions of the different subjects and respond to the deserved epistemic merit of their achievements. This mismatch can be produced by what we can call 'deforming forces' in the credibility space. The use of our epistemic concepts in our attributions is entangled with a complex social reality in which different power relations can affect the distribution of credibility. That is why someone using the concept of knowledge needs to understand that there can be a gap between a sufficiently good epistemic position and a social normative status merely derived from the difference of perspectives in the game of giving and asking for reasons. Being blind to the practices of power that are at the core of some of our epistemic institutions encourages those views that tend to accept that epistemic concepts do not track any real epistemic position for which a subject deserves some (epistemic) merit.

I think that if one accepts expressivist views that just reflect an interplay of perspectives in our epistemic vocabulary, as Brandom seems to do, a dilemma looms large. We have here two options: we could accept that there is nothing in the idea of deserving credit for the epistemic position a subject stands in, because there is no distance between the credibility judgements others are disposed to ascribe and her epistemic position. In this case, we are blind to the distorting forces in our space of recognized epistemic authorities. Alternatively, we would have to accept that there is a real distinction between authoritarian and authorized epistemic practices (Fricker 1998), and that this distinction entails that epistemic authority is not just a sort of social status. If it is a normative social status, it is one that we need to take to be grounded on certain ways of attaining truth, those which the subject deserves some credit for.

\section{Acknowledging and sharing epistemic authority}

As I have said, my purpose in this paper is not to provide a new practical explanation of the concept of knowledge. My methodological strategy is mainly based on taking into account actual uses of the concept and what we do by using it. Many authors do not take seriously the use of the concept in first-person ascriptions. This is, 
by contrast, my starting point: what do we do by applying the term in the first-person? Some expressivists and deflationists about firstperson discourse think that 'know' does not add any content to our assertions when these are understood as (implicit) claims to know. First-person uses do not respond to the registering of a "mental state" or "condition" and do not consist in informing others of one's own mental condition. At most, they make explicit the implicit knowledge claims we are already making by asserting that $p$. But making explicit, I contend, is not without consequences.

I follow recent views that have recovered classical remarks on the use of the concept of knowledge by Austin and defended that by affirming that one knows one is performing a distinctive speech act that it is not just asserting what one knows or making explicit an implicit knowledge claim. Krista Lawlor (2013) talks of an act of assurance. Let's remember Austin on this: "When I say I know, I give others my word: I give others my authority for saying that $\mathrm{S}$ is $\mathrm{P}$ " (Austin 1949: 171). In making an explicit claim of knowledge we are performing a speech act of assurance. The performance of this speech act goes with a series of commitments and responsibilities, some of them shared with assertions, such as the commitment to the truth of $p$ and the responsibility to the rational defense that $p$.

Nevertheless, there are at least two other distinctive features associated with our first-personal use of the concept of knowledge. First, I am addressing others and in doing that I offer to them my epistemic authority on whether $p$, in such a way that if they accept my word they will be in a sufficiently good (epistemic) position to assert that $p$ (in general, to use the proposition that $p$ in theoretical and practical reasoning). In giving my word, I am passing my authority to others (McMyler 2010). I am assuming, first, that the other would be disposed to share my reasons in favor of $p$. Second, I am adopting a certain attitude towards my own epistemic position. There are different ways of spelling out what this attitude amounts to. Lawlor explains it like follows: I represent myself as having reasons that others would find adequate, meaning conclusive reasons for the truth of $p$, such that I can guarantee it (Lawlor 2013). I favor the following formulation: in making explicit my knowledge-claims, what I am doing is making explicit my engagement in securing the truth. That means that the correctness of my explicit claim requires for me to be in a 
position to answer to my own involvement in the cognitive task of attaining the truth that $p$. This requires from me a certain acknowledgement that I am in such an epistemic position. This acknowledgment goes together with the acceptance of obligations towards others; I am responsible towards others of the truth that $p$. This, I hold, is a sort of practical acknowledgement that is exhibited in our explicit knowledge-claims. Practically acknowledging that I am in a position to know that $p$ is not just couched in terms of (socially distributed) attitudes; it is a way of being aware of how our beliefs adequately respond to reasons that (maybe conclusively) ground the truth of the proposition believed. It is this practical acknowledgement that in turn grounds my telling as a way of sharing authority with others.

This use of the notion of knowledge exhibits an ineliminable social dimension, insofar as it creates a sort of institutional link between epistemic agents. By explicitly claiming that $I$ know, I am adopting a responsibility towards others that goes with a certain demand of recognition of my authority on a certain subject matter. My explicit use of the concept creates a certain obligation in the addressee who must adequately respond to my giving the word on $p$ and having adopted this responsibility in securing the truth that $p$. First-person uses have a practical and social dimension; they show how a cognitive being has placed herself within a domain of normative demands.

Third-person uses confirm this point. Each use exhibits an acknowledgment that the other person is placed in a sufficiently good epistemic position, a position in which she has complied with socially shared normative demands. The third person is someone that others may/should regard as an epistemic authority regarding the proposition $p$. In a context where it matters how we gather and share information (as Craig and other have proposed), it is valuable to have a term that helps us to mark whether other people are trustworthy in such a way that you are not to be blamed if you were to take her word as authoritative on the question of whether $p$. To say that someone knows goes with a (practical) acknowledgment within a social space that she is someone you should be disposed to share knowledge with and recognize her epistemic authority on the issue. Collectively, it is our way of expressing the acknowledgment we owe to others because of her being creditably engaged in the task of knowing.

So by using the concept of knowledge we are not just marking 
the epistemic position others occupy, we are also granting them epistemic authority and indicating the advisability of taking them as "ready" for the transmission of authority. This acknowledgement goes with an endorsement of the normative standards that the community recognizes as compelling for the epistemic subjects. The very notion of knowledge shapes our understanding as knowers, that is, it contributes to transform the practices that constitute the epistemic domain by viewing agents as particularly concerned with the fulfillment of those standards. It marks cognitive agents as particularly engaged in securing the truth. Moreover, the concept of knowledge is one of the resources that we normally use in our effort of selfunderstanding. We could use a (slightly modified) quotation by Robert Brandom to insist on this point: logical and epistemic concepts function as organs of self-consciousness (2009: 11); they provide us with a particular way in which human beings conceive of themselves — and this is crucial — as taking part in a social and cultural niche of knowers.

Understanding ourselves as knowers is a condition for us to enter into the space of reasons. Our capacity as knowers has evolved in a particular cultural niche, where it matters how the performance of a cognitive task has been carried out and how others see this performance. In this niche, that is ab initio social and cultural, a need for assessment grows. Taking others as knowers is a way to identify those performances that are creditable to the epistemic agent and so serve as authority for others. As we learn what it is to be a knower through our experience with others, we need to deploy a concept like that of knowledge in order to be part of a community of knowers and acquire human knowledge. Briefly, the concept of knowledge serves to normatively indicate those positions in the social epistemic space of credibility that others can use authoritatively. By so using it, we are also implicitly projecting the space of perceived epistemic credibility to a real space of deserved epistemic positions under the assumption that they do never perfectly match. The reality of knowledge cannot be severed from our use of the concept in the human cultural niche where we live and experience the contrast between our own perspective on the world and the perspectives of others with which we can share knowledge. Our concept of knowledge is a tool that helps us to organize our inquiry and cognitive activities in a social and 
cultural niche. We assess the endeavours of other cognitive agents, and consider that they answer to a set of normative standards, in such a way that their satisfaction makes them creditable for the acquisition of truth. I think that this is coherent with a sort of pragmatism that is neither instrumental nor rationalist. ${ }^{3}$

Jesús Vega-Encabo Facultad de Filosofía y Letras Crta. Colmenar km. 15,4 28049 MADRID (Spain) jesus.vega@uam.es

\section{References}

Austin, J. 1949. Other minds. Supplement to the Proceedings of the Aristotelian Society 20: 148-87.

Beebe, J. R. 2012. Social functions of knowledge attributions. In Knowledge Ascriptions, edited by Jessica Brown and Mikkel Gerken. Oxford: Oxford University Press: 220-242.

Blackburn, S. 1984. Knowledge, truth and reliability. Proceedings of the British Academy: 167-87.

Brandom, R. 1994. Making it Explicit. Cambridge (Mass.): Harvard University Press.

Brandom, R. 2000. Articulating Reasons. Cambridge (Mass.): Harvard University Press.

Brandom, R. 2009. Reason in Philosophy. Cambridge (Mass.): Harvard University Press.

Brandom, R. 2010. Varieties of Pragmatism. Cambridge (Mass.): Harvard University Press.

Craig, E. 1990. Knowledge and the State of Nature. Oxford: Clarendon Press.

Fricker, M. 1998. Rational authority and social power. Towards a truly social epistemology. Proceedings of the Aristotelian Society 98(2): 159-178.

Gerken, M., Kallestrup, J., Kappel, K. and Pritchard, D. 2011. Introduction. Social cognitive ecology and its role in social epistemology. Special issue of

${ }^{3}$ I am indebted to many people for fruitful discussions on this topic: Fernando Broncano, Ernest Sosa, Josep Corbí, Javier González de Prado, and Neftalí Villanueva. I also want to thank the audiences of the VII SEFA Conference held in Madrid (September 2013) and the I Blasco Disputatio held in Valencia (November 2015) where I presented previous versions of this paper. This research has been funded by the Spanish Ministry of Economy and Competitivenss through the research grants FFI2013-45659-R; FFI2014-55256-REDT. 
Episteme 8(1): 1-5.

Greco, J. 2012. A (different) virtue epistemology. Philosophy and Phenomenological Research 85(1): 1-26.

Kappel, K. 2010. On saying that someone knows: themes from Craig. In Social Epistemology, edited by Adrian Haddock, Alan Millar, and Duncan Pritchard. Oxford: Oxford University Press: 69-88.

Kelp, C. 2011. What's the point of 'knowledge' anyway? Episteme 8(1): 53-66. Kusch, M. 2011. Knowledge and certainties in the epistemic state of nature. Episteme 8(1): 6-23.

Lawlor, K. 2013. Assurance. An Austinian View of Knowledge and Knowledge Claims. Oxford: Oxford University Press.

McMyler, B. 2010. Testimony, Trust and Authority. Oxford: Oxford University Press.

Nagel, J. 2014. Knowledge. A very short introduction. Oxford: Oxford University Press.

Rorty, R. 1979. Philosophy and the Mirror of Nature. Princeton: Princeton University Press.

Sosa, E. 2007. A Virtue Epistemology. Oxford: Oxford University Press. Sosa, E. 2011. Knowing Full Well. Princeton: Princeton University Press. Sosa, E. 2015. Judgment and Agency. Oxford: Oxford University Press. 